\title{
Failure Analysis and Diagnosis of Spark Erosion Machine Tools
}

\author{
H. Meng \\ A VIC Shenyang Liming Aero-Engine Group Corporation \\ China \\ N. Xin \\ A VIC Shenyang Liming Aero-Engine Group Corporation \\ China
}

\begin{abstract}
In recent years, along with the rapid development of industrial technology, the development of spark erosion technique becomes very important and plays a key role in the molding processing technology, especially under the situation when this technology is urgently needed. Based on the first-hand data from the production site, it is introduced here regarding the structure and the working principle of hcd500k spark erosion machine tool; at the same time, the common faults and problems of the pulse power and servo feed system are analyzed in details and proposed the solution on them. The detailed analysis is also given for the problems like the frequent poor discharge. The reasons and diagnosis methods are deeply studied as well. It is very helpful and supportive on providing evidence for minimizing the machine design defects and making continuous improvement in design. This paper is meaningful in helping machine tooling design to step into a higher level and having spark erosion machine tooling been improving continuously.
\end{abstract}

Keywords-spark erosion processing; diagnosis; design defects makeup; solution

\section{INTRODUCTION}

At the beginning of this century, scientific technology continued the momentum of the last century and maintained its development with high speed. Many products were updated into next generation frequently. New products emerged, from aircraft, cruise, to mobile phones, watches. Various kinds of high and new technology products, went into people's life directly or indirectly, bringing great convenience to people. However, along with these new products, market competition became more and more severe, which required higher and higher service from them. The traditional machining technology could not meet the high leveled needs for new products manufacture any more. In order to increase the competition ability, various advanced and new technology were applied to the manufacture of new products. As one of key methods in non-traditional processing technology, electrical spark machining technology, with its own characteristics and advantages, plays a more and more important role in more fields.

\author{
H. Guo \\ AVIC Shenyang Liming Aero-Engine Group Corporation \\ China \\ L. Zhang \\ A VIC Shenyang Liming Aero-Engine Group Corporation \\ China
}

\section{BRIEF INT RODUCTION OF HCD500K SPARK EROSION FORMING}

HCD500K CNC spark erosion forming machines, equipped with MD20D power supply cabinet, is mainly used for processing various types of molding like metal parts, molders, etc. The host machine adopts vertical lathe bed, horizontal working table, in single column "C" type structure. Three axis driven power adopts ac servo motor. The driven system is composed of the precise linear rolling guide and precise ball screw and bearing. With an excellent response in ac servo motor speed, torsional resistance is very strong. The $\mathrm{Z}$ axis ac servo motor is equipped with braking device. When power is on, the brake will be loose, so the servo control can be realized on the spindle head. When the power is off, the brake will be tightened to lock the spindle. The machine liquid tank is installed with double doors, which is a greatly convenient structure for clamping and finding electrode. With pumping connector and movable magnetic blunt oil block, oil flushing process can be realized at any angel and any place.

\section{A. Failure Analysis and Diagnosis of HCD500K Spark Erosion Forming Machine}

Due to high utilization and flexible processing way, the HCD500K spark erosion forming machine is very important for the completion of site production. However, during the process of usage, frequently occurred problems influence the equipment application seriously. Therefore, in this paper, we discussed the data out of the equipment failures in the production process, and proposed reasonable solutions, which provided the reliable data for later machine design and improvement.

\section{B. Abnormal Electro Discharge Machining}

Poor discharge machining performances are artifact burning, over-speedy machining, seriously exceeding normal processing speed, and even failure of normal discharge. There are many reasons for this kind of failure. The main problems occur on the facts including pulse power circuit board, power supply, circuit board, dc power supply, high power diode, and even on wire, jigs, etc. In addition, the problems also come from machining conditions and processing parameters. The 
following items are the factors affecting the discharge machining.

(1) the influence of pulse peak electric current

(2) the influence of the pulse width

(3) The influence of the inter pulse processing

(4) the influence of the media

\section{Power Tube Connection Failure. Abnormal Current Machining}

Power tube interface signal, which is driven by U38, U39 (SN74LS245) on the interface board, isolated by the $6 \mathrm{~N} 137$ optocoupler and again driven by 7406,4049 , controls the open and the close of the corresponding power tube after deleting the grid of the power tube on the board.

In case of failure occurred, check first the working status of the IP0 - IP16 luminous tube on the pulse power board. If the tube status cannot changed regularly, this means that the control signal of electrical current works normally from the main control board to the interface board. The problem comes from the power board. Continue to check the power board. By the IP0-IP32 signal, the light coupling piece U40-U56 signal is measured, and then there is no output signal from U46, which results in no output from IP5 causing no output from the fieldeffect tube DIP5 (IRFP44). Replacement with a new 6N137 film solves the problem.

\section{Processing Size Exceeding Tolerance}

In processing the translation function can be used to realize the expanding function, but the machined parts do not have round holes, so this means that the motor does not move normally in the translational axis X, Y.

The backstepping detection is the way how to solve the problem. The method is to test starting from the driver control signal, till to the master plate. First, switch the control signal on the $\mathrm{X}, \mathrm{Y}$ axis, and verify the point of failure. The result shows the same problem, meaning the driver works well. Second, check the driven film of the interface board, switch U21 and $\mathrm{U13}$, and the result changed, meaning the problem comes from U21 and U31. Replacement with a new U13 (US26LS31), the problem is solved. This means U13 film has been damaged.

\section{DAT A AN ANALYSIS ON FAILURE FREQUENCY}

Graph has its own characteristics in expression. Especially for something like time, space and else like abstract thinking, it can transfer info with the effects that written or verbal words cannot replace. The data listed in the columns and rows in the worksheet can be mapped into the line chart, which can show serial data changing with time. Therefore, graph is very suitable for displaying the data trend in different time intervals. In the line chart, category data and value data is distributed in uniform separately along the horizontal axis and vertical axis.

According to the analysis results summarized from onsite data, the failure rate will be high in case that the machine tool failed due to abnormal discharge processing and power failure; the failure rate will be low in case that the machine tool failed due to the deviation tolerance is exceeded in processing current and sizes. In order to make sure that the problems mentioned above can be solved by the upcoming designing, failure causes should be taken into consideration for later improvements during designing machine tools.

Failure frequency data, for example:

TABLE I. FALURE FREQUENCY DATA.

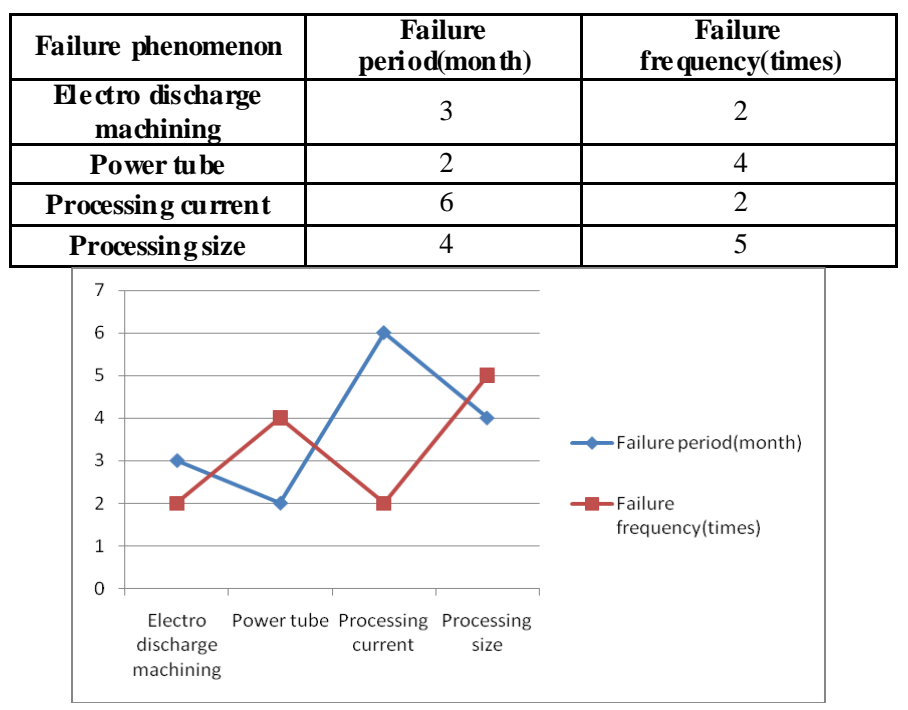

FIGURE I. FAILURE PERIOD, FREQUENCY ANALYSIS.

\section{SUMMARY}

HCD500K spark erosion machine has advanced structural design with good stability, high precision, simple operation, strong control and high production efficiency, etc. According to the data of the problem occurred in the production process, it can be seen that there is high failure rate with the power tube and the over-tolerance in processing, low failure rate with current processing by discharge machining. In view of the failure frequency mentioned above and in order to ensure a more completeness of the subsequent machine design, this article proposed a series of solutions after studying and analyzing the data out of the failures and problems by spark erosion machine tool working on production site. At the same time, many examples are shown for the further improvement of equipment design as great support and assistance for improving machine design.

\section{REFERENCES}

[1] Pailong Zhu; Changzheng Wei and Zhiyuan Wen; Approach and electrode study of deep hole large depth to diameter ratio[J], journal of mechanical en gineering $(2006)$.

[2] Xueke Luo, Yuezhong Li, CNC EDM machine tool (2004).

[3] Wansheng Zhao, EDM Technology Haierbin Industrial University press(2007).

[4] Ketokivi M.Sehroeder $\mathrm{R}$ Manufacturing practices.strategic fit and performance:A routine based view(2004).

[5] Mills, j. latts K.G regory M Aframework for the design of manufacturing strategy the Processes. A contingency approach(1995).

[6] Zhenhui Liu, Jiajie Yang. Special processing [M]. Chongqing University Press(2000).

[7] Jicheng Bai, Yongfeng Guo, Jinchun Liu. Special Processing Technology [M], Harbin Industrial University Press(2006).

[8] Zhen Li, Advanced Manufacturing Technology, Beijing University of Science and Technology Press(2009). 